\title{
Por uma Moeda Parcialmente Conversível: Uma Crítica a Arida e Bacha*
}

\author{
For a partially convertible currency: \\ A critique to Arida and Bacha
}

\author{
JOSÉ LUÍS OREIRO** \\ LUIZ FERNANDO DE PAULA ${ }^{+}$ \\ GUILHERME JONAS C. DA SILVA++
}

\begin{abstract}
RESUMO: O objetivo deste artigo é fazer uma avaliação crítica da hipótese de Arida-Bacha de que um prêmio de alto risco sobre a dívida externa e interna brasileira é consequência da conversibilidade limitada da conta de capital brasileira. Argumenta-se no presente trabalho que esta hipótese não é fundamentada nem em bases teóricas ou empíricas. A literatura teórica de conversibilidade da conta de capital não estabelece relação entre os controles de capital e o prêmio de risco sobre a dívida interna ou externa. A experiência recente da economia brasileira mostra que as taxas de juros reais ainda são muito altas, apesar da crescente liberalização da conta de capital. Testes econométricos envolvendo o prêmio de risco sobre a dívida externa brasileira e os índices de liberalização da conta de capital desenvolvidos por Cardoso e Goldfjan (1998) mostram que essas variáveis não cointegram. Assim, não é possível estabelecer a existência de uma relação de longo prazo entre a liberalização da conta de capital e o prêmio de risco, como seria de se esperar se a hipótese de Arida-Bacha estivesse correta.
\end{abstract}

PALAVRAS-CHAVE: Taxa de juros; prêmio de risco; conversibilidade do real; liberalização.

ABSTRACT: The objective of this article is to do a critical evaluation of Arida-Bacha hypothesis that a high-risk premium on external and internal Brazilian debt is the consequence of the limited convertibility of Brazilian capital account. It is argued in the present paper that this hypothesis is not grounded neither in theoretical or empirical basis. The theoretical litera-

\footnotetext{
* Os autores agradecem as sugestões feitas por Alfredo Saad Filho e Gilberto Tadeu Lima. Evidentemente, erros e omissões são de nossa inteira responsabilidade.

* Professor adjunto do Departamento de Economia da Universidade Federal do Paraná -UFPR, Curitiba/PR, Brasil. E-mail: joreiro@sociais.ufpr.br. Pesquisador do CNPq.

+ Professor adjunto da Faculdade de Ciências Econômicas da Universidade do Estado do Rio de Janeiro - UERJ, Rio de Janeiro/RJ, Brasil. E-mail: Ifpaula@alternex.com.br. Pesquisador do CNPq.

${ }^{++}$Mestrando em desenvolvimento econômico pela Universidade Federal do Paraná - UFPR, Curitiba/ PR, Brasil. E -mail: guilhermejonas@yahoo.com.br.
} 
ture of capital account convertibility establishes no relation between capital controls and risk-premium on internal or external debt. The recent experience of the Brazilian economy shows that real interest rates are still too high, despite the growing liberalization of the capital account. Econometric tests involving risk-premium on Brazilian external debt and indexes of capital account liberalization developed by Cardoso and Goldfjan (1998) shows that these variables do not co-integrate. Thus, it is not possible to establish the existence of a long-run relationship between capital account liberalization and risk-premium, as would be expected if Arida-Bacha hypothesis was correct.

KEYWORDS: Interest rate; risk premium; convertibility of the real; liberalization. JEL Classification: E11; E 43.

\section{INTRODUÇÃO}

Em artigos publicados nesta revista, Pérsio Arida (2003a e 2003b) e Edmar Bacha (2003) defendem que a consolidação da estabilidade macroeconômica no Brasil requer uma moeda plenamente conversível, uma vez que "os mecanismos de controle cambial, típicos do regime de câmbio controlado, sobreviveram à mudança de regime cambial" (Arida, 2003b, p. 152), como, por exemplo, a manutenção da separação entre os dois mercados de câmbio (o comercial e o financeiro). ${ }^{1}$ Mais especificamente, o aprofundamento do tripé hoje vigente de políticas - superávit fiscal primário expressivo, taxas de juros balizadas pela meta inflacionária e câmbio flutuante - requer um programa gradual de erradicação dos controles no mercado de câmbio.

Para esses autores a plena conversibilidade, ao afastar o risco de reintrodução de controles cambiais por via administrativa, resultaria em menores taxas de juros em dólares dos títulos de longo prazo no exterior e, conseqüentemente, menores taxas em reais, em função da existência de uma relação positiva entre prêmio de risco e controles de capitais.

No que segue, procuramos demonstrar que tal hipótese carece de uma sustentação teórica e empírica mais consistente, seja porque a literatura sobre liberalização financeira não estabelece uma relação de causalidade entre controle de capitais e prêmio de risco, seja porque parece não haver evidência empírica que dê suporte a tal causalidade, de acordo com alguns testes econométricos feitos ao final deste artigo.

\section{OS ARGUMENTOS CENTRAIS DE ARIDA E BACHA}

A hipótese central de Arida e Bacha é que a manutenção de controles administrativos às transações com moeda estrangeira faz com que as taxas de juros interna

\footnotetext{
${ }^{1}$ Segundo Arida (2003a, p.137), “uma das características essenciais dos regimes com conversibilidade restrita é a faculdade concedida ao Banco Central de alterar as normas do mercado cambial de acordo com os requisitos de política econômica”.
} 
e externa no Brasil sejam mais altas do que prevaleceria numa situação de plena conversibilidade. Daqui se segue que a eliminação desses controles - com a introdução de um regime de livre conversibilidade nas transações no mercado de câmbio $^{2}$ - é uma estratégia complementar à obtenção dos elevados superávits primários na tarefa de redução do endividamento público como proporção do PIB à medida que taxas de juros internas e externas mais baixas permitiriam (i) um superávit primário mais baixo, e (ii) um nível de investimento mais alto por parte das empresas domésticas e, portanto, um maior crescimento econômico. ${ }^{3}$

O eixo central da hipótese Arida/Bacha é, portanto, que as restrições adminis-trativas às transações com moeda estrangeira aumentam as taxas de juros interna e externa devido ao seu efeito sobre o prêmio de risco, o que acaba gerando a necessidade de superávits primários ainda maiores. Em outras palavras, o prêmio de risco depende, entre outros fatores, do regime de conversibilidade da moeda doméstica. Nas palavras de Arida (2003a, p. 141, grifos no original):

“Os elevados prêmios de risco, interpretados pelo Banco Central como resultantes de avaliação exógena do mercado sobre os fundamentos e justificadores portanto de sua prudência, em boa medida refletem a leitura de que ele, o Banco Central, está sinalizando ao próprio mercado [...] O círculo vicioso faz com que os prêmios de risco permaneçam elevados e suba por conseqüência o superávit primário necessário para estabilizar a moeda. Dito de outra forma: a estabilização com conversibilidade restrita exige um superávit fiscal maior do que o necessário sob livre conversibilidade."

Os efeitos da conversibilidade restrita sobre as taxas reais de juros se dão de duas formas interdependentes:

- Efeito sobre o prêmio de risco externo: a manutenção de um regime de conversibilidade restrita sinaliza para os credores externos a possibilidade de o Banco Central suspender ou contingenciar os pagamentos ao exterior no futuro. Dessa forma, o risco de default dos compromissos externos das empresas domésticas aumenta, gerando uma elevação da taxa de juros off-shore.

- Efeito sobre o prêmio de risco interno: sendo válida a "paridade descoberta da taxa de juros", a taxa de juros nominal doméstica deve ser igual à soma da taxa de juros internacional, o risco-país e a expectativa da desvalorização cambial. Portanto, pelo efeito acima referido haveria um aumen-

\footnotetext{
${ }^{2}$ É preciso ressaltar que o que os autores estão sugerindo é uma liberalização (total) do mercado de câmbio, que viria a reforçar a liberalização da conta capital do balanço de pagamentos.

${ }^{3}$ Nas palavras de Bacha (2003, p. 150): “com a conversibilidade, completar-se-ia a trilogia monetária buscada pelo Plano Real. Além da unidade de conta e de meio de troca, a moeda própria do país, flutuante em relação ao dólar, passaria a ser uma legítima reserva de valor. Com base nela, poder-se-ia então construir um sistema financeiro interno com contratos de longo prazo, superando-se, assim, a condição de vulnerabilidade externa que persegue o país desde os primórdios da industrialização".
} 
to no risco-país e/ou uma expectativa de uma depreciação excessiva da moeda doméstica devido ao risco de imposição de restrições à liberdade de capitais, o que resultaria em patamares mais elevados das taxas reais de juros domésticas. Visto de outra forma, a manutenção de um regime de conversibilidade restrita sinalizaria para os credores internos a pouca confiança que o próprio Tesouro tem na sua capacidade de honrar os compromissos financeiros devidos à dívida interna. Essa sinalização tem o efeito de aumentar o prêmio de risco sobre os títulos da dívida interna, fazendo com que a taxa de juros interna também se eleve.

Segundo Arida e Bacha, uma das vantagens da livre conversibilidade é que o Banco Central não seria mais obrigado a manter reservas em divisas, uma vez que o mercado cambial é livre para os agentes que compram e vendem dólares com base em suas expectativas sobre o comportamento da taxa nominal de câmbio. Já na conversibilidade restrita estaria implícita a mensagem de que em certas circunstâncias pode não haver reservas suficientes para sustentar o câmbio.

Um aspecto secundário da argumentação de Arida e Bacha é que os controles administrativos sobre as transações em moeda estrangeira são vistos como uma "solução ineficiente" para os problemas de volatilidade cambial que são provocados pelas imperfeições nos mercados de câmbio. A solução ótima seria a realização de intervenções esporádicas do Banco Central no mercado de câmbio (dirty floating), com o objetivo de suavizar as flutuações cambiais geradas por movimentos de manada e bolhas especulativas.

Em conclusão, os controles administrativos aos fluxos de moeda estrangeira não trariam nenhum benefício para a economia na forma de redução da volatilidade cambial, mas imporiam um custo elevado na forma de taxas de juros interna e externa elevadas.

\section{CRÍTICAS AOS ARGUMENTOS DE ARIDA E BACHA}

Em primeiro lugar, os argumentos defendidos por Arida e Bacha são de natureza eminentemente iconoclasta, uma vez que a tese de que o prêmio de risco depende do regime de conversibilidade da conta de capitais parece não ter respaldo na literatura internacional ou nacional sobre o referido tema. Com efeito, a literatura sobre conversibilidade da conta de capitais não aponta a redução do prêmio de risco como um dos potenciais benefícios da liberalização financeira.

Os potenciais benefícios da liberalização financeira seriam de outra ordem, estando relacionados, entre outros fatores, ao acesso dos países emergentes a mercados financeiros externos em condições mais favoráveis, aprimorando a alocação de poupança a nível mundial, à pressão para melhoria na supervisão financeira dos mercados financeiros domésticos, ao acesso ao know-how tecnológico e conhecimento de melhores práticas de outros países via investimentos diretos estrangeiros, e ainda por exercer uma força disciplinadora via mercado sobre as políticas ma- 
croeconômicas entendidas como inconsistentes. Em outras palavras, a liberalização na conta capital levaria, em princípio, à melhoria na eficiência da alocação de recursos, estimulando o crescimento econômico, ainda que possa ter eventualmente efeitos instabilizadores sobre o mercado cambial e financeiro. ${ }^{4}$ Nas palavras de Fischer (1998, p. 3):

"Em suma, a liberalização da conta de capital pode trazer benefícios significativos para os países. Residentes e governos são capazes de tomar emprestado em termos mais favoráveis, e os mercados financeiros domésticos tornam-se mais eficientes como resultado da introdução de tecnologias financeiras mais avançadas, resultando em uma melhor alocação de poupanças e investimentos (...) Ao mesmo tempo, a liberalização da conta capital aumenta a vulnerabilidade da economia a mudanças do sentimento. Geralmente, essas mudanças têm base racional, mas elas podem ser na ocasião excessivas e podem algumas vezes resultar em efeitos de contágio.

O que a literatura de liberalização financeira mostra - como Fischer sugereé que a abertura da conta capital permite aos países emergentes captar recursos mais baratos no exterior em relação ao mercado financeiro doméstico devido ao fato de que a produtividade marginal do capital é mais baixa nos países desenvolvidos do que nos países emergentes, tendo em vista a maior oferta de capital nos países desenvolvidos. Em outras palavras, o capital tende a ser mais barato nos países onde ele é mais abundante, e daí resulta a explicação do diferencial de taxas de juros nos mercados financeiros entre países. Essa explicação, contudo, não estabelece uma relação direta entre prêmio de risco e conversibilidade da conta capital.

Adiciona-se, ainda, que Arida e Bacha não apresentam nenhuma evidência empírica que suporte a hipótese de que o prêmio de risco é afetado pelo regime de conversibilidade da conta de capitais. A experiência histórica mostra precisamente o contrário do que argumentam esses autores: ao longo da década de 90, o Brasil caminhou na direção de uma conversibilidade crescente da conta de capitais, sem que houvesse uma tendência de redução no risco-país ou na taxa real de juros

\footnotetext{
${ }^{4}$ A liberalização financeira tem sido objeto de fortes críticas por diversos economistas, em função dos efeitos negativos da volatilidade dos fluxos de capitais sobre a estabilidade macroeconômica (volatilidade na taxa de câmbio e na taxa de juros, impactos negativos sobre investimento, produção e emprego etc.) e da não-existência de uma relação clara entre liberalização financeira e crescimento econômico (ver, entre outros, Rodrik, 1998; Tobin, 2000; Stiglitz, 2000). Rodrik (1998), por exemplo, ao examinar a relação entre liberalização financeira, por um lado, e crescimento econômico e estabilidade, por outro, concluiu que: "os dados não oferecem nenhuma evidência de que países em desenvolvimento sem controle de capitais tenham crescido mais rápido, investido mais ou experimentado inflação menor. Controles de capitais são essencialmente não correlacionados com o desempenho econômico no longotermo, uma vez que controlemos outros determinantes" (p. 61). Por outro lado, um recente estudo feito por economistas do FMI conclui que: “[...] um exame sistemático das evidências sugere que é difícil estabelecer uma relação causal robusta entre integração financeira [isto é, liberalização da conta capital] e desempenho do crescimento do produto" (Prasad et al, 2003, p. 6).
} 
doméstica. ${ }^{5}$ Possivelmente o alto grau de abertura da conta capital no Brasil é um dos fatores que contribuem para que a taxa nominal e real de juros no país esteja entre as mais altas do mundo. A trajetória da taxa real de juros no Brasil de 1995 a 2003 mostra que o único evento que atuou de forma decisiva para mudar o patamar de "equilíbrio" da taxa real de juros foi a mudança do regime cambial brasileiro em janeiro de 1999, e ainda assim a taxa de juros reais tem se mantido, em geral, em patamares elevados, superiores a $9 \%$ a. $\mathrm{a}^{6}$ (ver Gráfico 1).

Gráfico 1: Taxa de Juris no Brasil (1995-2003)

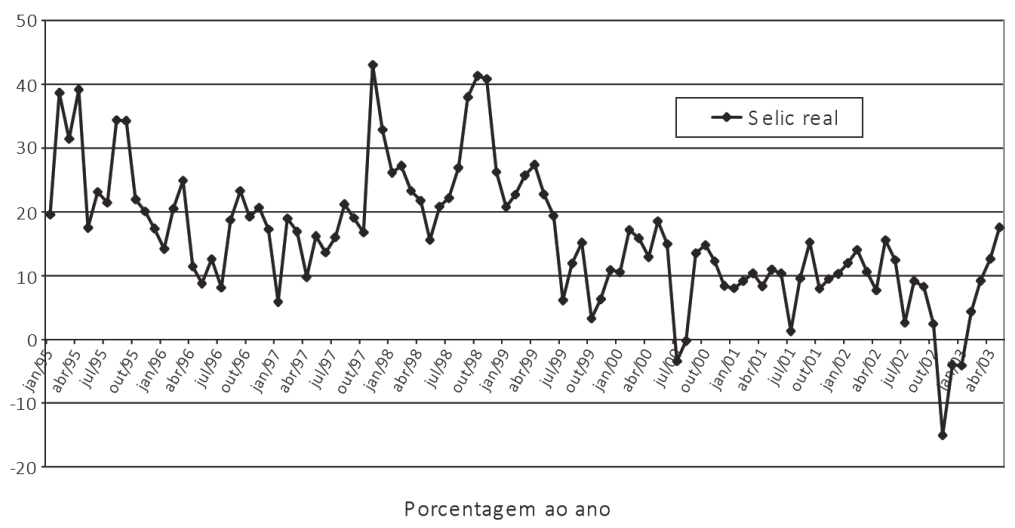

Fonte: Cálculo dos autores com base em dados do Banco Central do Brasil ${ }^{7}$

No apêndice deste artigo efetuamos um exercício econométrico - por meio de análise de regressão e testes de co-integração - que procurou investigar a influência dos controles de capitais sobre o risco-país no período 1994-2000. Os resultados alcançados rejeitam a hipótese de Arida/Bacha de existência de uma relação direta entre as mudanças nos controles administrativos em relação à conversibilidade da moeda nacional e à variação do prêmio de risco-país. Tampouco se observou a existência de uma relação de longo prazo entre o prêmio de risco e o nível dos controles de entrada e saída de capitais no Brasil no período recente.

Por outro lado, a relação entre conversibilidade e prêmio de risco pode se dar precisamente no sentido inverso ao proposto por Arida e Bacha. De fato, podemos imaginar que uma situação na qual a expectativa de que o Banco Central vai "apertar" os controles administrativos em caso de uma "parada súbita" ${ }^{8}$ - isto é, uma

\footnotetext{
${ }^{5}$ Ver Gráfico 2.

${ }^{6}$ Extrapola os objetivos deste artigo discutir os motivos pelos quais os juros reais têm se mantido tão altos no Brasil, apesar da adoção de um regime de taxa de câmbio flutuante. Ver, a respeito, BresserPereira e Nakano (2002).

${ }^{7}$ Os autores agradecem ao estudante Rafael Coutinho (UFPR) a ajuda prestada na construção da série de tempo para a taxa real de juros (selic-real) usada no presente trabalho.

${ }^{8}$ Sobre o "efeito parada súbita" ver Calvo (1998) e Licha (2000).
} 
situação de reversão abrupta e acentuada nos fluxos de capitais causadas por mudanças nos "sentimentos do mercado" que tende a gerar situações de crises externas — pode criar nos agentes econômicos (internos ou externos) a convicção de que:

a) a volatilidade cambial induzida por comportamentos de manada será relativamente baixa, de forma que os devedores domésticos não enfrentarão problemas de solvência, devido ao aumento do valor, em moeda doméstica, dos seus compromissos externos em épocas de maior especulação cambial;

b) o Banco Central não deverá engendrar um aumento significativo na taxa dejuros doméstica como resposta ao "efeito parada súbita", de forma que a queda de emprego, renda e arrecadação tributária resultante desse fenômeno deverá ser menor do que seria em condições de livre conversibilidade. Em qualquer um desses cenários, contudo, o prêmio de risco será mais baixo do que ocorreria numa situação de plena conversibilidade.

Arida e Bacha parecem negligenciar os efeitos causados pela grande mobilidade e excessiva volatilidade dos capitais de curto prazo em um contexto de conta capital aberta. Os problemas de gerenciamento macroeconômico devido aos efeitos da instabilidade dos fluxos de capitais já preocupavam James Tobin, em artigo de 1978: "Eu acredito que o problema básico hoje não é o regime cambial, se fixo ou flutuante. O debate sobre regimes obscurece o problema essencial, que é a excessiva mobilidade internacional (...) do capital financeiro privado" (Tobin, 1978, p.153, itálicos acrescentados). De fato, em um contexto de grande mobilidade de capitais de curto prazo, crises do balanço de pagamentos podem ocorrer por razões não diretamente relacionadas com a situação da conta de transações correntes do balanço de pagamentos (Calvo, 2001). Em outras palavras, países que possuem pequenos déficits em transações correntes como proporção do PIB - e que, portanto, são solventes do ponto de vista externo (Eaton, 1993) - podem se defrontar com uma reversão súbita da entrada de capitais de curto prazo em função de uma mudança nas expectativas dos investidores internacionais. Essa mudança de expectativas pode ser induzida por eventos não fundamentais (sunspots) ou pode ainda resultar de comportamentos de manada (herding behavior) ou ainda do chamado efeito contágio. Eventos não fundamentais (sunspots) - como rumores — podem desencadear uma crise externa de graves conseqüências sobre as economias dos países nos quais não há restrições ao movimento de entrada e saída de capitais de curto prazo. ${ }^{9}$

Por fim, o argumento de que a volatilidade cambial pode ser "resolvida" pelas intervenções esporádicas do Banco Central no mercado de câmbio ignora uma questão fundamental, que é a de que, se a estabilização do mercado de câmbio tiver que ser feita unicamente por meio das operações de compra e venda de moeda estrangeira pelo Banco Central, então este terá que, ao contrário do que sugerem

\footnotetext{
${ }^{9}$ Nossa contribuição quanto ao assunto pode ser vista em Alves Jr., Ferrari Filho e Paula (1999/2000) e Oreiro (2001).
} 
Arida e Bacha, manter um volume de reservas em moeda estrangeira muito maior do que seria necessário caso tivesse a sua disposição instrumentos administrativos para conter ou controlar os fluxos de entrada e saída de moeda estrangeira. Daqui se segue que um pré-requisito importante para a viabilidade do regime de plena conversibilidade é a existência de um grande volume de reservas em moeda estrangeira, o que é extremamente problemático em países, como o Brasil, que têm uma elevada relação dívida externa/PIB, o que resulta em uma pressão permanente para o pagamento de um elevado montante de divisas relacionadas à amortização e serviço da dívida.

Possivelmente a volatilidade cambial iria aumentar no Brasil por ocasião da adoção de um regime de conversibilidade plena, deixando o país refém das mudanças de humores do mercado financeiro internacional. A taxa de câmbio não é um preço qualquer: tanto sua volatilidade quanto sua apreciação/depreciação excessiva têm efeitos instabilizadores sobre as expectativas empresariais, uma vez que o câmbio é dos preços básicos que balizam o cálculo empresarial (tal como salário e taxa de juros), arrefecendo, conseqüentemente, o animal spirit dos empresários, com efeitos negativos sobre o nível de investimentos (Davidson, 1982). No caso dos países emergentes, como é o caso do Brasil, o problema é maior devido ao reduzido tamanho de seus mercados de capitais com relação aos fluxos de capitais de curto prazo que ingressam neles, o que resulta em uma elevada oscilação nos fluxos de divisas tanto na conta capital quanto nas rendas relacionadas aos serviços financeiros da conta corrente. Tal fato faz com que nos países emergentes a volatilidade cambial seja bem maior do que nos países desenvolvidos. ${ }^{10}$ Esses países enfrentam, ainda, problemas derivados de uma apreciação acelerada na taxa de câmbio real, que pode resultar de fluxos excessivos de capitais externos. Adicionalmente, a volatilidade da taxa de câmbio em países emergentes resulta também dos problemas associados ao financiamento de elevados déficits em conta corrente no balanço de pagamentos de um país, que pode levar a uma crescente demanda por hedge cambial em momentos de maior incerteza no cenário nacional e/ou internacional.

\section{CONCLUSÃO}

Conclui-se que não existem argumentos de natureza teórica ou empírica que sustentem a tese de que a plena conversibilidade da conta de capitais traria consigo

\footnotetext{
${ }^{10}$ Segundo Greenville (2000), os problemas de volatilidade cambial são mais sérios quando se trata de países emergentes, uma vez que: (i) não têm uma experiência histórica de taxas de câmbio determinadas pelo mercado; (ii) há poucos especuladores estabilizadores atuando no mercado de câmbio, ou seja, há uma ausência de players desejosos de atuar em posições cambiais contrárias à da média do mercado, além de esses mercados serem propensos a exibir uma mentalidade de manada (herd behavior); (iii) apresentam fluxos de capitais muito maiores e mais voláteis em relação ao tamanho dos mercados de capitais domésticos.
} 
uma redução significativa dos prêmios de risco e das taxas de juros interna e externa, podendo mesmo gerar efeitos inversos aos levantados por Arida e Bacha. Os resultados alcançados nos testes econométricos realizados nos anexos deste artigo sugerem não ser adequado ao Brasil a adoção de um regime de plena conversibilidade.

Há, contudo, um outro regime de conversibilidade possível, que vai na direção contrária à apontada pelos autores: introduzir controles seletivos de capitais — por meio, por exemplo, de um recolhimento compulsório não remunerado pelo período de um ano ${ }^{11}$ - a fim de (i) permitir uma maior autonomia da política monetária ao se desvincular a taxa de juros doméstica do valor estabelecido pela "paridade descoberta da taxa de juros"; (ii) contribuir para um maior equilíbrio do saldo em transações correntes do balanço de pagamentos, ao impedir que a entrada de grandes fluxos de capital no país gere uma forte apreciação da taxa real de câmbio e (iii) diminuir a volatilidade no mercado cambial, visando melhorar as condições de administração da política monetária e cambial. ${ }^{12}$

Um dos méritos dos trabalhos de Arida e Bacha é suscitar uma discussão acadêmica aberta a respeito de qual regime de conversibilidade é mais desejável para o Brasil. Acreditamos que tal discussão deve ser feita aprofundando tanto os argumentos teóricos quanto os argumentos empíricos sobre o assunto, sem perder de vista o foco da discussão, que é avaliar qual regime deve ser o mais apropriado para o Brasil para alcançar uma política macroeconômica mais consistente e efetivamente estabilizadora. O presente trabalho objetivou dar uma contribuição a esse debate.

\section{REFERÊNCIAS BIBLIOGRÁFICAS}

ALVES Jr., A.J., FERRARI FILHO, F. e Paula, L.F. (1999-2000). “The post Keynesian critique of conventional currency crisis models and Davidson's proposal to reform the international monetary System”. Journal of Post Keynesian Economics, 22 (2): 209-227, Inverno.

ARIDA, P. (2003a). “Ainda a conversibilidade”. Revista de Economia Política, 23 (3): 135-142, jul./set. (2003b). "Por uma moeda plenamente conversível”. Revista de Economia Política, 23(3): 151-154, jul./set.

\footnotetext{
${ }^{11}$ Esse tipo de controle foi utilizado no Chile nos anos 90 e combinou controles baseados no mercado (por meio de taxação indireta sobre os fluxos de capitais via requerimentos de reserva, que variou de 10 a $30 \%$ ) com controles administrativos (requerimento de tempo mínimo para os fluxos de entrada de capitais) e outras medidas regulatórias (como a obrigatoriedade de um rating mínimo para tomada de empréstimos externos). Ainda que não haja evidências conclusivas de que houve uma redução na magnitude do influxo de capitais no Chile na referida década e que, conseqüentemente, tenha tido efeito sobre a taxa de câmbio real, há consenso de que o controle de capitais ajudou a alongar a maturidade média desses fluxos (Valdés e Soto, 1996; Edwards, 1999) e também permitiu, por meio dos requerimentos de reserva não renumerados, aumentar, em algum grau, a autonomia da política monetária, ao ajudar a manter uma separação entre as condições monetária doméstica e internacional (Ariyoshi et al., 2000, cap. V).

12 Uma proposta mais detalhada para adoção de controle de capitais no Brasil, que foge ao escopo deste artigo, é feita em Paula, Oreiro e Silva (2003).
} 
ARIYOSHI, A., K. HABEMEIER, B. LAURENS, I. TKER-ROBE, J. CANALES-KRILJENKO, e A. Kirilenko (2000). Capital Controls: Country Experiences with Their Use and Liberalization. Washington: IMF.

BACHA, E. (2003). "Reflexões pós-cepalinas sobre inflação e crise externa". Revista de Economia Politica, 23 (3): 143-150, jul./set.

BARBOSA, F. H. e A. S. LOUREIRO (2003). "The risk premium on Brazilian government debt: 19962002”. Ensaios Econômicos EPGE, n. 485.

BRESSER-PEREIRA, L. C. e Y. NAKANO (2002). "Uma estratégia de desenvolvimento com estabilidade". Brazilian Journal of Political Economy, 22 (3): 146-177, jul./set.

CALVO, G. (1998). "Capital flows and capital-market crises: the simple economics of sudden stops". Journal of Applied Economics, 1 (1):.35-54.

(2001). "Crises de balanços de pagamentos em mercados emergentes". In Krugman, P. (org.). Crises Monetárias. São Paulo: Makron Books.

CARDOSO, E. e I. GOLDFAJN. (1998). "Capital flows to Brazil: the endogeneity of capital controls". IMF Staff Papers, vol. 45, n.1: 161-202, março.

CASTELLAR, P.V. (2001). “A política cambial brasileira: o caráter endógeno dos controles de capitais de curto prazo no Brasil” (1994-1999). Dissertação de Mestrado, IE-UFRJ.

DAVIDSON, P. (1982). International Money \& The Real World, $2^{\mathrm{a}}$ ed. Londres: MacMillan.

EATON, J. (1993). "Sovereign debt: a primer". The World Bank Economic Review, 7 (2).

EDWARDS, S. (1999). "How effective are controls on capital flows? An evaluation of Chile's experience", mimeo.

FISCHER, S. (1998). "Capital account liberalization and the role of the IMF". Essays in International Finance n. 207: 1-10, Princeton.

GRENVILLE, S. (2000). "Exchange rate regimes for emerging markets". Reserve Bank of Australia Bulletin: 53-63, novembro.

KEYNES, J.M. (1964). The General Theory of Employment, Interest and Money. New York: Harcourt Brace.

LICHA, A. (2000). "Volatilidade de capitais de curto prazo em países emergentes”. Instituto de Econo$\mathrm{mia} / \mathrm{UFRJ}$, mimeo.

OREIRO, J.L. (2001). "Bolhas, incerteza e fragilidade financeira: uma abordagem pós-keynesiana”. Revista de Economia Contemporânea, 5 (2): 7-45, jul./dez.

PAULA, L.F., J. L. OREIRO e G. J. SILVA (2003). "Fluxos e controle de capitais no Brasil: avaliação e proposição de política”. In Sicsú, J., Oreiro, J.L. e Paula, L.F., orgs. Agenda Brasil: políticas econômicas para o crescimento com estabilidade de preços. Barueri/SP: Editora Manole.

PRASAD, E., K. ROGOFF, S. WEI e M. KOSE (2003). "Effects of financial globalization on developing countries: some empirical evidence", mimeo (www.imf.org).

RODRIK, D. (1998). "Who needs capital-account convertibility?" Essays in International Finance, no. 207: 55-65, Princeton.

SOIHET, E. (2002). "Índice de controle de capitais: uma análise da legislação e dos determinantes de fluxo de capital no Brasil no período 1990-2000”. Dissertação de mestrado. Rio de Janeiro: FGV/EPGE.

STIGLITZ, J. (2000). "Capital market liberalization, economic growth and instability”. World Development, 28 (6): 1075-1086.

TOBIN, J.(1978). “A proposal for international monetary reform”. Eastern Economic Journal, vol. 4. . (2000). "Financial globalization”. World Development, 28 (6): 1101-1104.

VALDÉS, S. e M. SOTO (1996). "Es el control selectivo de capitales efectivo en Chile? Su efecto sobre el tipo de cambio real”. Cuadernos de Economía, 33 (98): 77-108. 


\section{ANEXO 1}

RISCO-PAÍS E CONTROLE DE CAPITAIS:

EVIDÊNCIAS A PARTIR DO CASO BRASILEIRO (1994-2000)

Este Anexo tem por objetivo investigar empiricamente a influência da dívida pública como proporção do PIB e do controle de capitais sobre o risco-país. ${ }^{13}$ Para tanto, foi realizada uma coleta dos dados no período de 1994-2000 com base em informações disponíveis na JP Morgan, em Soihet (2002), no Instituto de Pesquisa Econômica Aplicada (www.ipeadata.gov.br) e no Banco Central (www.bcb.gov.br).

$\mathrm{O}$ indicador que mensura o grau de controle de capitais foi extraído do trabalho de Cardoso e Goldfajn (1998), o qual denominamos de Índice de Controle de Capitais (ICC). Esses autores construíram indicadores cuja proposta é medir as mudanças mensais ocorridas na legislação que afetam o fluxo de capital por meio das alterações ocorridas no controle à entrada e à saída de capital.

Segundo Cardoso e Goldfajn (1998), a construção de indicadores a partir de medidas relacionadas à saída de capital pode ter efeitos ambíguos sobre o fluxo de capital. Em um primeiro momento, a restrição à saída de capital leva à manutenção do fluxo. Porém, uma medida de cunho restritivo pode também levar os investidores a perceber que essas restrições futuramente serão uma ameaça às remessas de seus retornos ao exterior, podendo resultar em uma redução do fluxo de capital. O efeito final sobre os fluxos líquidos das restrições sobre saída de capitais dependerá da força relativa das respostas das saídas de capitais.

Seguindo Cardoso e Goldfajn (1998), há duas medidas de controle de capital, $\Delta C C_{1}$ e $\Delta C C_{2}$, definidas como combinações lineares de mudanças nas restrições sobre fluxos de saída e fluxos de entrada de capitais: ${ }^{14}$

$$
\begin{aligned}
& \Delta C C_{1}=\Delta R I-0,5 . \Delta R O \\
& \Delta C C_{2}=\Delta R I+0,5 . \Delta R O
\end{aligned}
$$

sendo que (i) $\Delta R I$ é uma medida de restrição sobre fluxos de entrada de capitais, em que uma mudança na legislação que venha a reduzir tais fluxos, como um aumento no IOF sobre entrada de capitais, recebe valor igual a 1 , enquanto uma mudança na legislação direcionada para o aumento dos fluxos de entrada de capitais recebe um valor igual a -1 ; (ii) $\Delta R O$ é uma medida de variação das restrições sobre a entrada de capitais, em que qualquer mudança na legislação que vise afetar

\footnotetext{
13 O risco-país é calculado tomando-se como base o diferencial de juros de um título do governo norteamericano (tido como risco zero) e título do governo de um país, negociados no mercado internacional, com a mesma maturidade.

${ }^{14}$ Ambos os indicadores, $\Delta C C_{1}$ e $\Delta C C_{2}$, permitem respostas contrárias nos fluxos de entrada e saída de capitais à mudança em $\Delta R O$ ao estabelecer um peso neste de 0,5 : a primeira medida assume que restrições sobre saída de capitais têm um impacto maior sobre a saída do que sobre a entrada de capitais, enquanto a segunda medida assume que o impacto das restrições sobre saída de capitais sobre os fluxos de entrada predomina sobre o efeito dessas restrições sobre os fluxos de saída.
} 
a redução nos fluxos de saída de capitais recebe valor igual a 1 e qualquer mudança que liberalize a saída de capitais recebe o valor igual a -1 .

Analisando-se a evolução dos dois indicadores acima em 1990/2000, pode-se observar que houve - como tendência geral - uma gradual e crescente abertura da conta de capital da economia brasileira no período, confirmando os achados de Cardoso e Goldfajn (1998), Castellar (2001) e Soihet (2002). Em termos gerais, os controles de capitais foram endógenos no Brasil: o governo reagia à entrada de capitais, aumentando o controle nos períodos de boom, principalmente via cobrança de IOF sobre os ganhos de aplicações financeiras de investidores externos no país, e liberalizando nos períodos de crise. ${ }^{15}$ Conforme observa Soihet (2002, seção 3.2), de janeiro de 1990 a julho de 1994 a maioria das medidas relacionadas a controle de capitais foi liberalizante, enquanto de agosto de 1994 a dezembro de 1996 houve um misto de medidas liberalizantes e medidas restritivas; já a partir de 1997, a trajetória se inverteu, com claro predomínio de medidas liberalizantes. De fato, como se pode perceber com base no Gráfico 2, o caráter endógeno dos controles de capitais parece bastante evidente, sendo que, em particular, a partir de 1997, em função das sucessivas pressões especulativas sobre o real, houve um nítido incentivo por parte do governo à entrada e manutenção de capital no país.

Gráfico 2 - Índice de Controle de Capitais (1990-2000)

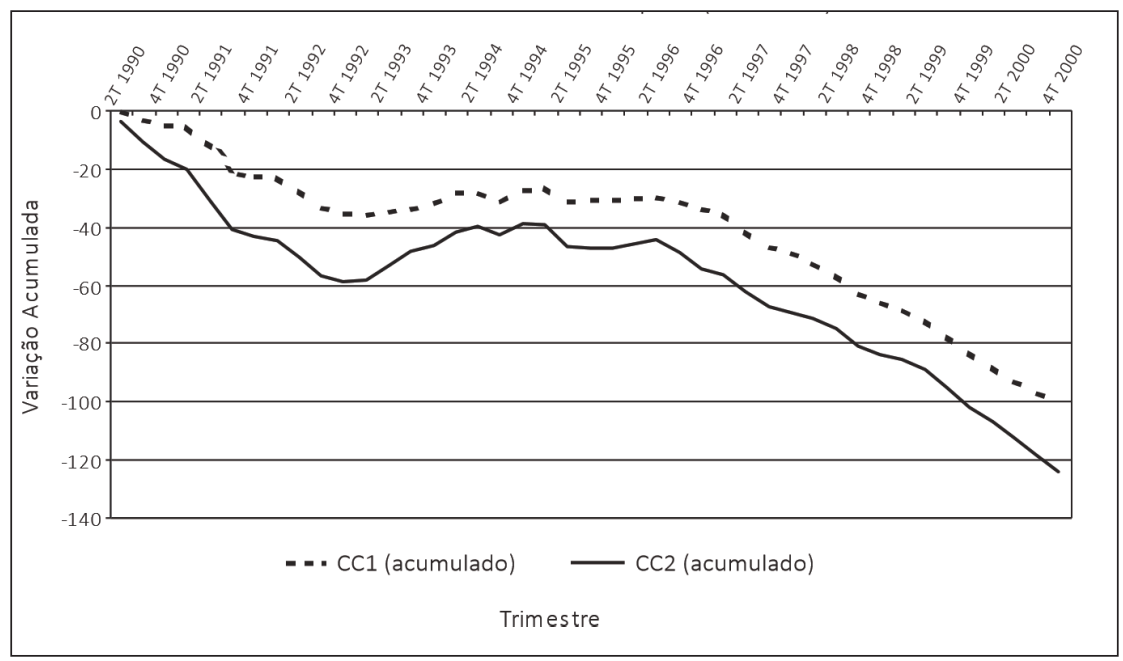

Fonte: Tabela 4

Para efeito do exercício econométrico, selecionamos dados mensais no período de 1994-2000 das seguintes variáveis: dívida pública/PIB, $\mathrm{CC}_{1}$ e $\mathrm{CC}_{2} \cdot{ }^{16}$ Utilizamos

\footnotetext{
15 Durante a década de 90, alguns controles sobre entrada de capitais foram temporariamente estabelecidos em períodos excepcionais de elevada oferta de capitais externos, mas os controles sobre saída de capitais foram completamente liberalizados.
}

${ }^{16}$ Os dados trimestrais dessas variáveis estão na Tabela 2. 
o método dos mínimos quadrados ordinários (MQO), onde estimamos as seguintes equações:

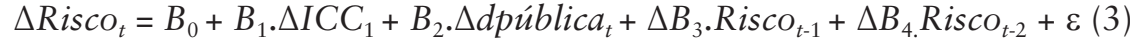

$$
\begin{aligned}
& \Delta \text { Risco }_{t}=B_{0}+B_{1} \cdot \Delta I C C_{2}+B_{2} \cdot \Delta d p u ́ \text { blica }_{t}+\Delta B_{3} \cdot \text { Risco }_{t-1}+\Delta B_{4} \cdot \text { Risco }_{t-2}+\varepsilon(4)
\end{aligned}
$$

Onde $\Delta R$ isco refere-se à variação do risco-país; $\Delta I C C_{1}$ capta o impacto negativo das variações das restrições à saída de capitais sobre o fluxo líquido de entrada de capital; $\triangle I C C_{2}$ capta o impacto positivo das restrições à saída de capitais sobre o fluxo líquido de entrada de capital e $\Delta d p u ́ b l i c a$ é a variação da dívida pública como proporção do PIB. Apesar de a amostra ser relativamente pequena, pode-se verificar a partir da análise de regressão a veracidade ou não da hipótese Arida/Bacha de que o risco-país é, em parte, dependente das medidas de controle de capitais.

Tendo em vista que as séries temporais das variáveis em questão são estacionárias apenas em primeira diferença, as regressões foram trabalhadas utilizando-se a primeira diferença.

Tabela 1: Variável dependente: $\Delta$ Risco (1994-2000)

(1)

$-12,00$

$(-0,79)$

$-9,95$

$(-1,14)$
$(2)$

\begin{tabular}{|c|c|c|}
\hline$\triangle \mathrm{CC} 1$ & $\begin{array}{l}-9,95 \\
(-1,14)\end{array}$ & - \\
\hline$\triangle \mathrm{CC} 2$ & - & $\begin{array}{l}-9,15 \\
(-1,25)\end{array}$ \\
\hline \multirow{2}{*}{$\triangle$ dpública } & 21,81 & 21,61 \\
\hline & $(2,17)$ & $(2,16)$ \\
\hline \multirow{2}{*}{$A R(1)$} & 0,17 & 0,18 \\
\hline & $(-1,54)$ & $(1,61)$ \\
\hline \multirow{2}{*}{$A R(2)$} & $-0,17$ & $-0,18$ \\
\hline & $(-1,57)$ & $(-1,64)$ \\
\hline $\mathrm{R} 2$ & 0,17 & 0,17 \\
\hline R2 ajustado & 0,12 & 0,13 \\
\hline
\end{tabular}

Nota: As regressões não apresentaram problemas de heterocedasticidade. No tocante à autocorrelação serial, foi corrigida incorporando-se os vetores auto-regressivos ao modelo. As séries foram estacionárias apenas na primeira diferença. Devido ao fato de ter sido detectada multicolinearidade entre $\triangle \mathrm{CC}_{1}$ e $\triangle \mathrm{CC}_{2}$, estimamos separadamente duas equações de regressão, a primeira envolvendo $\triangle \mathrm{CC}_{1}$ e a segunda envolvendo $\triangle \mathrm{CC}_{2}$. 
A Tabela 1 apresenta os resultados da estimação para o período de 19942000. Percebe-se que apenas a dívida pública como proporção do PIB foi significativa a $5 \%$. Os vetores auto-regressivos foram significativos apenas ao nível de $10 \%$, evidenciando que o comportamento passado do prêmio de risco pode ser uma variável explicativa importante na determinação da variação do risco. ${ }^{17}$ Os resultados obtidos indicam também que a probabilidade de variações dos controles administrativos sobre os fluxos de entrada e saída de capitais - cuja evolução no tempo é mostrada pelos índices $\mathrm{ICC}_{1}$ e $\mathrm{ICC}_{2}-$ não gerarem variações do prêmio de risco é muito alta (superior a $21 \%$ ). Esse resultado nos leva a rejeitar a hipótese Arida/Bacha de existência de uma relação direta entre as mudanças dos controles administrativos em relação à conversibilidade da moeda nacional e a variação do prêmio de riscopaís. Com efeito, a única variável, além do componente auto-regressivo do prêmio de risco, estatisticamente significativa no exercício de regressão realizado é a variação da dívida pública como proporção do PIB. ${ }^{18}$

Adicionalmente ao teste realizado foram feitos dois testes de co-integração envolvendo o prêmio de risco-país e os índices de controles de capitais ICC $_{1}$ e $\mathrm{ICC}_{2}$. O objetivo desses testes é avaliar a existência de uma relação de longo prazo entre prêmio de risco e nível dos controles de entrada e saída de capitais. Sendo válida a hipótese Arida/Bacha, deveria existir uma relação de longo prazo entre as variáveis em consideração. Tal como podemos observar nas Tabelas 2 e 3 , a seguir, deve-se rejeitar a hipótese de co-integração entre as referidas variáveis ao nível de significância de $1 \%$ tanto no caso de $\mathrm{ICC}_{1}$ como no caso de $\mathrm{ICC}_{2}$. Dado isso, parece não haver suporte empírico para a hipótese Arida/Bacha de existência de uma relação positiva entre o prêmio de risco e os controles de capitais para o caso da economia brasileira no período 1994-2000.

\footnotetext{
17 Esse resultado pode indicar que os investidores internacionais formam suas expectativas sobre o riscode default do país com base na hipótese de expectativas adaptativas, dando pouca importância a outras variáveis que não o histórico do prêmio de risco. Sobre a racionalidade desse tipo de comportamento, ver Keynes (1964, cap.12).

${ }^{18}$ Esse resultado dá um suporte parcial à visão fiscalista sobre o porquê de as taxas de juros serem tãoaltas no Brasil. Com efeito, os resultados obtidos mostram que cada ponto percentual de aumento da dívida pública interna como proporção do PIB gera um aumento de cerca de 21,6 pontos-base no prê-mio de risco-país. Sendo válida a hipótese da paridade descoberta da taxa de juros, esse aumento do prêmio de risco se traduzirá em aumento da taxa de juros doméstica ou em depreciação do câmbio nominal. O suporte é parcial, contudo, pois os resultados dos testes econométricos apontam a presença de um componente auto-regressivo na formação do prêmio de risco ao nível de significância de aproximadamente $10 \%$. Sobre a visão fiscalista da taxa de juros no Brasil, ver Barbosa e Loureiro (2003).
} 
Tabela 2: Resultados do Teste de Co-integração entre o Prêmio de Risco

e o Índice de Controle de Capitais ICC 1 - Planilha do Eviews

Date: 10/14/03 Time: 13:13

S ample: 1994:01 2000:12 Included observations: 80

Test assumption: Linear deterministic trend in the data

Series: RIS CO ICC

Lags interval: 1 to 2

\begin{tabular}{|c|c|c|c|c|}
\hline & Likelihood & 5 Percent & 1 Percent & Hypothesized \\
\hline Eigenvalue & Ratio & Critical Value & Critical Value & No. of $\mathrm{CE}(\mathrm{s})$ \\
\hline 0.088611 & 10.00553 & 15.41 & 20.04 & None \\
\hline 0.031768 & 2.582662 & 3.76 & 6.65 & At most 1 \\
\hline \multicolumn{5}{|c|}{$\begin{array}{l}*(* *) \text { denotes rejection of the hypothesis at } 5 \%(1 \%) \text { significance level } \\
\text { L.R. rejects any cointegration at } 5 \% \text { significance level Unnormalized Cointegrating } \\
\text { Coefficients: }\end{array}$} \\
\hline \multicolumn{5}{|c|}{ 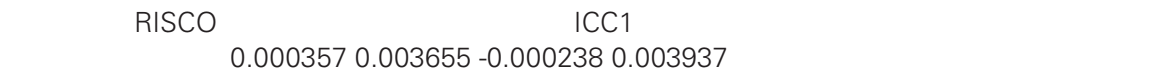 } \\
\hline \multicolumn{5}{|c|}{ Normalized Cointegrating Coefficients: 1 Cointegrating Equation(s) } \\
\hline RISCO & ICC1 & & $\mathrm{C}$ & \\
\hline 1.000000 & $\begin{array}{l}10.24843 \\
(6.40643)\end{array}$ & & -620.6981 & \\
\hline Log likelihood & -629.2955 & & & \\
\hline
\end{tabular}

Tabela 3: Resultados do Teste de Cointegração entre o Prêmio de Risco

e o Índice de Controle de Capitais $\mathrm{ICC}_{2}$ — Planilha do Eviews

Date: 10/14/03 Time: 13:39

S ample: 1994:01 2000:12 Included observations: 80

Test assumption: Linear deterministic trend in the data

S eries: RIS CO ICC

Lags interval: 1 to 2

\begin{tabular}{|c|c|c|c|c|}
\hline & Likelihood & 5 Percent & 1 Percent & Hypothesized \\
\hline Eigenvalue & Ratio & $\begin{array}{l}\text { Critical } \\
\text { Value }\end{array}$ & $\begin{array}{l}\text { Critical } \\
\text { Value }\end{array}$ & No. of CE(s) \\
\hline 0.084142 & 10.87627 & 15.41 & 20.04 & None \\
\hline 0.046923 & 3.844745 & 3.76 & 6.65 & At most $1^{*}$ \\
\hline \multicolumn{5}{|c|}{$\begin{array}{l}\left.*^{* *}\right) \text { denotes rejection of the hypothesis at } 5 \%(1 \%) \text { significance level } \\
\text { L.R. rejects any cointegration at } 5 \% \text { significance level Unnormalized Cointegrating } \\
\text { Coefficients: }\end{array}$} \\
\hline RISCO & & $\mathrm{ICC}_{2}$ & & \\
\hline 0.000266 & & 0.003749 & & \\
\hline 0.000327 & & -0.002740 & & \\
\hline
\end{tabular}




\begin{tabular}{ccc}
\hline Normalized Cointegrating Coefficients: & 1 Cointegrating Equation(s) \\
\hline RISCO & $\mathrm{ICC}_{2}$ & $\mathrm{C}$ \\
& 14.07634 & -457.7692 \\
1.000000 & $(10.1753)$ & \\
Log likelihood & -645.5477 & \\
\hline
\end{tabular}

Tabela 4: Base de dados usada nos testes econométricos

\begin{tabular}{|c|c|c|c|c|}
\hline Discriminação & RISCO & $\mathrm{ICC}_{1}$ & $\mathrm{ICC}_{2}$ & DPUB \\
\hline 199401 & 448.0000 & 0.000000 & 0.000000 & 31.00000 \\
\hline 199402 & 456.0000 & 2.000000 & 3.000000 & 31.00000 \\
\hline 199403 & 700.0000 & 1.000000 & 3.000000 & 32.00000 \\
\hline 199404 & 947.0000 & -1.000000 & 1.000000 & 33.00000 \\
\hline 199405 & 1005.000 & -1.000000 & 3.000000 & 34.00000 \\
\hline 199406 & 991.0000 & 0.000000 & 4.000000 & 35.00000 \\
\hline 199407 & 1027.000 & -1.000000 & 3.000000 & 35.00000 \\
\hline 199408 & 892.0000 & -2.000000 & 0.000000 & 34.00000 \\
\hline 199409 & 820.0000 & 3.000000 & 6.000000 & 33.00000 \\
\hline 199410 & 779.0000 & 8.000000 & 12.00000 & 32.00000 \\
\hline 199411 & 860.0000 & 8.000000 & 12.00000 & 31.00000 \\
\hline 199412 & 841.0000 & 7.000000 & 9.000000 & 30.00000 \\
\hline 199501 & 1060.000 & 6.000000 & 6.000000 & 30.00000 \\
\hline 199502 & 1129.000 & 2.000000 & 2.000000 & 31.00000 \\
\hline 199503 & 1460.000 & -1.000000 & -2.000000 & 33.00000 \\
\hline 199504 & 1328.000 & 1.000000 & -1.000000 & 33.00000 \\
\hline 199505 & 1098.000 & 0.000000 & -2.000000 & 34.00000 \\
\hline 199506 & 1137.000 & -1.000000 & -3.000000 & 31.00000 \\
\hline 199507 & 1084.000 & 0.000000 & -2.000000 & 30.00000 \\
\hline 199508 & 1082.000 & 0.000000 & -2.00000 & 29.000000 \\
\hline 199509 & 1021.000 & -1.000000 & -3.000000 & 30.00000 \\
\hline 199510 & 993.0000 & -1.000000 & -3.000000 & 30.00000 \\
\hline 199511 & 1089.000 & -1.000000 & -3.000000 & 30.00000 \\
\hline 199512 & 1020.000 & -1.000000 & -3.000000 & 31.00000 \\
\hline 199601 & 856.0000 & 1.000000 & -3.000000 & 30.00000 \\
\hline
\end{tabular}




\begin{tabular}{|c|c|c|c|c|}
\hline 199602 & 775.0000 & 2.000000 & -2.000000 & 30.00000 \\
\hline 199603 & 875.0000 & 3.000000 & -1.000000 & 28.00000 \\
\hline 199604 & 811.0000 & 3.000000 & -1.000000 & 27.00000 \\
\hline 199605 & 750.0000 & 2.000000 & -2.000000 & 28.00000 \\
\hline 199606 & 742.0000 & 2.000000 & -2.000000 & 29.00000 \\
\hline 199607 & 675.0000 & 2.000000 & -2.000000 & 29.00000 \\
\hline 199608 & 649.0000 & 1.000000 & -7.000000 & 30.00000 \\
\hline 199609 & 560.0000 & -1.000000 & -11.00000 & 31.00000 \\
\hline 199610 & 546.0000 & -1.000000 & -11.00000 & 32.00000 \\
\hline 199611 & 571.0000 & -2.000000 & -12.00000 & 33.00000 \\
\hline 199612 & 534.0000 & -3.000000 & -13.00000 & 33.00000 \\
\hline 199701 & 474.0000 & -4.000000 & -15.00000 & 34.00000 \\
\hline 199702 & 413.0000 & -5.000000 & -16.00000 & 34.00000 \\
\hline 199703 & 447.0000 & -6.000000 & -16.00000 & 34.00000 \\
\hline 199704 & 468.0000 & -8.000000 & -18.00000 & 34.00000 \\
\hline 199705 & 434.0000 & -12.00000 & -22.00000 & 34.00000 \\
\hline 199706 & 400.0000 & -15.00000 & -25.00000 & 33.00000 \\
\hline 199707 & 385.0000 & -15.00000 & -25.00000 & 33.00000 \\
\hline 199708 & 375.0000 & -15.00000 & -25.00000 & 33.00000 \\
\hline 199709 & 375.0000 & -15.00000 & -25.00000 & 33.00000 \\
\hline 199710 & 420.0000 & -17.00000 & -27.00000 & 33.00000 \\
\hline 199711 & 659.0000 & -19.00000 & -29.00000 & 33.00000 \\
\hline 199712 & 573.0000 & -19.00000 & -29.00000 & 34.00000 \\
\hline 199801 & 591.0000 & -19.00000 & -28.00000 & 35.00000 \\
\hline 199802 & 523.0000 & -20.00000 & -28.00000 & 35.00000 \\
\hline 199803 & 469.0000 & -23.00000 & -31.00000 & 36.00000 \\
\hline 199804 & 472.0000 & -24.00000 & -32.00000 & 36.00000 \\
\hline 199805 & 534.0000 & -26.00000 & -34.00000 & 36.00000 \\
\hline 199806 & 633.0000 & -28.00000 & -36.00000 & 37.00000 \\
\hline 199807 & 631.0000 & -31.00000 & -39.00000 & 38.00000 \\
\hline 199808 & 981.0000 & -34.00000 & -42.00000 & 38.00000 \\
\hline 199809 & 1398.000 & -34.00000 & -42.00000 & 39.00000 \\
\hline
\end{tabular}




\begin{tabular}{|c|c|c|c|c|}
\hline 199810 & 1299.000 & -35.00000 & -43.00000 & 40.00000 \\
\hline 199811 & 1064.000 & -35.00000 & -43.00000 & 41.00000 \\
\hline 199812 & 1256.000 & -36.00000 & -45.00000 & 42.00000 \\
\hline 199901 & 1507.000 & -37.00000 & -46.00000 & 51.00000 \\
\hline 199902 & 1385.000 & -38.00000 & -45.00000 & 51.00000 \\
\hline 199903 & 1248.000 & -40.00000 & -46.00000 & 48.00000 \\
\hline 199904 & 938.0000 & -41.00000 & -47.00000 & 48.00000 \\
\hline 199905 & 995.0000 & -42.00000 & -48.00000 & 50.00000 \\
\hline 199906 & 1053.000 & -45.00000 & -51.00000 & 51.00000 \\
\hline 199907 & 1121.000 & -49.00000 & -56.00000 & 51.00000 \\
\hline 199908 & 1210.000 & -50.00000 & -58.00000 & 52.00000 \\
\hline 199909 & 1091.000 & -50.00000 & -58.00000 & 51.00000 \\
\hline 199910 & 1000.000 & -50.00000 & -58.00000 & 51.00000 \\
\hline 199911 & 853.0000 & -52.00000 & -60.00000 & 50.00000 \\
\hline 199912 & 733.0000 & -56.00000 & -64.00000 & 49.00000 \\
\hline 200001 & 736.0000 & -58.00000 & -66.00000 & 50.00000 \\
\hline 200002 & 749.0000 & -59.00000 & -67.00000 & 50.00000 \\
\hline 200003 & 683.0000 & -62.00000 & -71.00000 & 50.00000 \\
\hline 200004 & 786.0000 & -63.00000 & -73.00000 & 51.00000 \\
\hline 200005 & 862.0000 & -63.00000 & -73.00000 & 51.00000 \\
\hline 200006 & 757.0000 & -63.00000 & -73.00000 & 50.00000 \\
\hline 200007 & 740.0000 & -66.00000 & -77.00000 & 49.00000 \\
\hline 200008 & 702.0000 & -68.00000 & -80.00000 & 48.00000 \\
\hline 200009 & 695.0000 & -69.00000 & -82.00000 & 49.00000 \\
\hline 200010 & 751.0000 & -69.00000 & -84.00000 & 49.00000 \\
\hline 200011 & 802.0000 & -68.00000 & -84.00000 & 49.00000 \\
\hline 200012 & 780.0000 & - & - & 49.00000 \\
\hline
\end{tabular}

Fonte: Cálculo dos autores com base em dados do J P Morgan (risco-Brasil), de S oihet (2002), do IPEA (www.ipeadata.gov.br) e do Banco Central do Brasil (www.bcb.gov.br). 